\title{
Avaliação de Produtos Alternativos no Controle da Ferrugem do Cafeeiro
}

\author{
Mauro J.N. Costa*, Laércio Zambolim \& Fabrício A. Rodrigues
}

Departamento de Fitopatologia, Universidade Federal de Viçosa, CEP 36571-000, Viçosa, MG, Brasil, e-mail:zambolim@ufv.br

Autor para correspondência: Laércio Zambolim

COSTA, M.J.N., ZAMBOLIM, L. \& RODRIGUES, F.A. Avaliação de produtos alternativos no controle da ferrugem do cafeeiro. Fitopatologia Brasileira 32:150-155. 2007.

\section{RESUMO}

Objetivou-se neste trabalho avaliar produtos orgânicos quanto ao efeito protetor e indutor de resistência à ferrugem do cafeeiro (Hemileia vastatrix), comparando-se com fungicidas sistêmicos. O trabalho foi desenvolvido em casa-de-vegetação, utilizando-se mudas de cafeeiro cv. Catuaí Vermelho 144. Foram avalidados como indutores de resistência extratos foliares, suspensões de conídios fúngicos e de células bacterianas, fertilizantes foliares, hipocloritos e acibenzolar-S-methyl (ASM). O delineamento experimental utilizado foi em blocos casualizados com três repetições, sendo que cada parcela experimental foi constituída de cinco mudas de café perfazendo um total de 15 mudas por tratamento. Os experimentos foram repetidos duas vezes com resultados semelhantes. Quando avaliado o efeito protetor, a maioria dos compostos reduziu o número de pústulas e a área foliar com ferrugem em comparação à testemunha 1 (água). Extratos de folhas de café, obtidos pelo processo aquoso e extratos de sementes de Azadirachta indica ("neem") obtidos pelo processo de extração com metanol apresentaram proteção similar, mas nunca superior a epoxiconazole + piraclostrobin. Extratos aquosos de folhas de café, ASM, Bacillus subtilis e Pseudomonas putida reduziram a infecção causada por H. vastatrix em mais de 77 \%.

Palavras-chave adicionais: controle alternativo de doenças, efeito protetivo, Coffea arábica, Hemileia vastatrix.

\begin{abstract}
Evaluation of alternative products and fungicides for the control of coffee leaf rust

The main objective of this study was to evaluate the use of organic products for their protective effect against coffee leaf rust (Hemileia vastatrix Berk. \& Br.) and also their ability to induce resistance, compared to systemic fungicides. This study was carried out under greenhouse conditions using the cv. 'Catuai Vermelho 144'. Leaf extracts, suspensions of fungal conidia and bacterial cells, foliar fertilizers, hypochlorites and acibenzolar-S-methyl (ASM) were evaluated as potential inducers of resistance. The experiment was installed in a complete randomized block design with three replications. Each experimental plot contained five coffee plants and each treatment had 15 plants. The experiments were repeated twice with similar results. With regard to the protective effect, most of the treatments decreased the number of pustules and the leaf area with rust in comparison to treatment 1 (leaves sprayed with water). Water extracts of coffee leaves and methanol extracts of seeds of Azadirachta indica ("neem”) gave similar results, but never better than the protection obtained by using epoxiconazole + piraclostrobin. Regarding induction of resistance, extracts of coffee leaves, ASM, Bacillus subtilis and Pseudomonas putida reduced the infection caused by $H$. vastatrix by more than $77 \%$.
\end{abstract}

Additional keywords: alternative control of diseases, protective effect, Coffea arábica, Hemileia vastatrix.

O controle químico da ferrugem do cafeeiro, causada pelo fungo Hemileia vastatrix Berk. \& Br., embora eficiente e econômico (Vegro \& Ferreira, 2000), mostrouse agressivo ao meio ambiente. Um dos maiores desafios para os pesquisadores é a constante busca por métodos alternativos de controle da ferrugem que causem menor impacto ambiental. A pesquisa direcionada à proteção de plantas utilizando substâncias e organismos indutores de resistência é uma alternativa promissora. Com o uso de agentes bióticos inoculados nas plantas hospedeiras, esta técnica permite a proteção contra o ataque de patógenos, através da ativação de mecanismos de defesa. Resistência induzida é um fenômeno local ou sistêmico e é efetivo contra

*Endereço Atual: Fundação Rio Verde, Cx. Postal 159, CEP 78455-000, Lucas do Rio Verde MT, Brasil, e-mail: maurolrv@hotmail.com uma ampla gama de patógenos, incluindo bactérias, fungos e vírus (Kessmann et al., 1994; Van Loon et al., 1998). A resistência induzida representa uma alternativa promissora para a utilização de genótipos suscetíveis, mas que possuem características agronômicas desejáveis, sem a alteração do genoma da planta (Stadnik, 2000).

Várias substâncias químicas e extratos com suposta atividade indutora são citados, incluindo vários sais inorgânicos, oxalato, fosfato, 2-thiouracil, ácido poliacrílico (Stein \& Loebenstein, 1972; Antoniw \& White, 1980), além de esporos de fungos não patogênicos, esporos fúngicos inativados e extratos vegetais (Martins, 1991). Em cafeeiros, a indução de resistência é uma tecnologia pouco explorada necessitando de maiores estudos. Desta forma, os objetivos do presente trabalho foram (i) avaliar os efeitos de suspensões orgânicas, adubos foliares e suspensões de esporos fúngicos ou bacterianos, na indução de resistência local e sistêmica 
à ferrugem; (ii) avaliar a capacidade de proteção de plantas de café cultivar Catuaí Vermelho por esses compostos; (iii) avaliar doses e épocas de aplicação desses produtos e (iv) comparar o efeito de indutores de resistência com o de fungicidas sistêmicos.

Mudas de cafeeiro Coffea arabica L. cv. Catuaí Vermelho 144, susceptíveis a todas as raças fisiológicas de Hemileia vastatrix, e possuindo, em média, 8 pares de folhas definitivas, foram obtidas de produtores na região de Viçosa MG. As mudas foram transplantadas para vasos plásticos contendo 2,0 Kg de substrato composto por solo, esterco de curral e areia $(2,5: 1: 0,5)$ acrescido de superfosfato simples $\left(5,0 \mathrm{~kg} / \mathrm{m}^{3}\right)$ e cloreto de potássio $\left(1,0 \mathrm{~kg} / \mathrm{m}^{3}\right)$, fumigado com brometo de metila $\left(150 \mathrm{~cm}^{3} / \mathrm{m}^{3}\right)$. As mudas permaneceram em casa-de-vegetação, com temperatura variando de $25 \pm 2$ ${ }^{\circ} \mathrm{C}$ e umidade relativa de $\pm 66 \%$.

Foram coletadas folhas de cafeeiro cv. Catuaí de lavoura no campo exibindo sintomas de ferrugem para obtenção de uredosporos. Os uredosporos foram removidos das pústulas com auxílio de pincel passados em peneiras de 0,42 $\mathrm{mm}$ de abertura de malha e a seguir foram acondicionados em ampolas de vidro vedadas com algodão. As ampolas foram colocadas em dessecador, contendo na parte inferior, solução aquosa de ácido sulfúrico (densidade de 1,8 e concentração de 32,6\% v/v), para manter a umidade relativa em torno de $50 \%$ (Zambolim \& Chaves, 1974). O teste de viabilidade dos uredosporos revelou uma porcentagem de germinação de $\pm 35 \%$.

Uredosporos de $H$. vastatrix foram transferidos para água destilada estéril na concentração de $4 \mathrm{mg} / \mathrm{mL}$. A suspensão foi autoclavada $\left(121{ }^{\circ} \mathrm{C}, 30 \mathrm{~min}\right)$ e depois filtrada de acordo com Costa et al. (2001). Os organismos Bacillus subtilis e Pseudomonas putida foram isolados de folhas de café conforme recomendações de Maringoni (1995). $B$. subtilis e $P$. putida foram mantidas em meio contendo ágar (2\%), peptona (1\%) e $\mathrm{NaCl}(0,5 \%)$ com $\mathrm{pH}$ de \pm $7,5)$. Suspensões de $B$. subtilis e $P$. putida foram obtidas adicionando-se $5 \mathrm{~mL}$ de água destilada estéril em cada placa de Petri contendo culturas puras, as quais foram ajustadas a seguir para $2 \times 10^{8}$ células $/ \mathrm{mL}$ (Abs $=800$ e $\lambda=620 \mathrm{~nm}$ ) seguido de armazenamento em geladeira $\left( \pm 5^{\circ} \mathrm{C}\right)$.

Folhas de café da cv. Catuaí Vermelho 144 e de 'neem' (Azadirachta indica A. Juss.) coletadas de plantas no campo foram lavadas com água de torneira para desinfestação superficial e secas a temperatura ambiente por um período de aproximadamente 12 hs. As folhas foram pesadas e cortadas em pedaços $\left( \pm 12 \mathrm{~cm}^{2}\right)$ para a obtenção dos extratos aquosos e/ou orgânicos. Para obtenção dos extratos aquosos foi utilizada a técnica de infusão a quente, na qual $40 \mathrm{~g}$ de folhas de cada material vegetal foram transferidas para um béquer contendo $1 \mathrm{~L}$ de água deionizada estéril aquecida até a temperatura de $\pm 35{ }^{\circ} \mathrm{C}$. A mistura permaneceu em repouso no escuro, durante 2 hs. Após o resfriamento, o extrato aquoso foi filtrado em funil de Büchner usando papel de filtro Whatman No. 1. O resíduo sólido foi eliminado e o extrato aquoso foi armazenado em geladeira. Para obtenção do extrato orgânico, $30 \mathrm{~g}$ de sementes de 'neem' foram trituradas e transferidas para $300 \mathrm{~mL}$ de hexano em balão de $500 \mathrm{~mL}$ acoplado a um condensador de refluxo. A mistura sofreu refluxo durante $15 \mathrm{~min}$ sob uma manta de aquecimento. Em seguida, filtrou-se a mistura obtendose a suspensão A. O resíduo retido no filtro permaneceu na câmara de exaustão para evaporação do solvente. O resíduo foi extraído com metanol nos mesmos procedimentos descritos anteriormente para obtenção da suspensão B. As suspensões A e B foram, separadamente, concentradas em evaporador rotatório sob pressão reduzida a $35^{\circ} \mathrm{C}$ até a remoção total dos solventes usados na extração. Os resíduos presentes no balão após a evaporação dos solventes foram dissolvidos em $1 \mathrm{~L}$ de água contendo Tween $(1 \%$, v/v). As suspensões obtidas foram armazenadas em câmara fria a $5^{\circ} \mathrm{C}$ até o momento da utilização.

O acilbenzolar-S-metil, os hipocloritos de sódio e cálcio, os fungicidas e os fertilizantes foliares foram adquiridos de fabricantes (Tabela 1) e, pulverizados na superfície abaxial do $2^{\circ}$ e $3^{\circ}$ par de folhas para verificar o efeito protetor ou sistêmico dos mesmos. Os produtos foram dispersos em água contendo polissorbato de cálcio (Tween 80) a $1 \%$, quando necessário, e as suspensões agitadas durante 10 min antes da pulverização. Uredosporos foram distribuídos na superfície abaxial de cada par de folhas com a ajuda de um pincel. Após a deposição do inoculo nas folhas, as plantas foram aspergidas com água destilada até se obter um leve molhamento superficial. Após o prazo de 4 horas e 8 dias da aplicação de produtos com possível efeito indutor de resistência sistêmica, plantas foram inoculadas com $H$. vastatrix. As plantas inoculadas foram mantidas no escuro durante 72 horas $\left(24{ }^{\circ} \mathrm{C}\right.$, UR $\left.90 \%\right)$ e depois transferidas para casa-de-vegetação até o aparecimento dos sintomas de ferrugem. A avaliação dos sintomas de ferrugem foi realizada após 60 dias da inoculação das plantas no $2^{\circ} \mathrm{e}$ $3^{\circ}$ par de folhas. Coletou-se um total de 12 folhas de cada tratamento (quatro folhas/planta em três plantas)/tratamento para determinação do número médio de pústulas por folha e a porcentagem da área foliar com ferrugem de acordo com uma escala desenvolvida por Kushalappa \& Chaves (1978). Área foliar foi medida utilizando-se o medidor fixo do modelo LI-3100, marca Licor.

O delineamento experimento utilizado foi em blocos casualizados com 36 tratamentos e três repetições. Os tratamentos variaram de acordo com o período estabelecido para inoculação das plantas após a pulverização com os produtos. Cada parcela experimental foi constituída por cinco mudas de café. Os dados do número médio de pústulas de ferrugem por folha e da porcentagem de área foliar com ferrugem foram submetidos à análise de variância e os tratamentos comparados pelo teste de Scott \& Knott ao nível de $1 \%$ de probabilidade.

Quando avaliado o efeito dos compostos, constatouse redução do número de pústulas bem como da área foliar com ferrugem, em comparação à testemunha 1 (água) $(P \leq 0,05)$, conforme mostra a Tabela 2 . Um total de dez 
TABELA 1 - Compostos utilizados na pulverização de mudas de café para determinação do efeito protetor ou sistêmico no controle da ferrugem do cafeeiro

\begin{tabular}{|c|c|c|}
\hline Especificação dos tratamentos & Nome Comercial & Empresa \\
\hline \multicolumn{3}{|l|}{ Extratos foliares ${ }^{1}$} \\
\hline 1 Folhas de café (A) & $\mathrm{I}^{2}$ & I \\
\hline 2 Folhas de Neem (A) & I & I \\
\hline 3 Sementes de Neem (A) & I & $\mathrm{I}$ \\
\hline $4 \quad$ Sementes de Neem $(\mathrm{H})$ & I & I \\
\hline $5 \quad$ Sementes de Neem (M) & I & $\mathrm{I}$ \\
\hline 6 Bioflavonóides cítricos, ácidos orgânicos, açúcares, etc. & Ecolife & Quinabra \\
\hline \multicolumn{3}{|l|}{ Suspensões de conídios ou de células bacterianas } \\
\hline $7 \quad H$. vastatrix (4mg/L de água) & I & $\mathrm{I}$ \\
\hline $8 \quad$ Bacillus subtilis (800Abs) & I & I \\
\hline $9 \quad$ Pseudomonas putida (800Abs) & I & I \\
\hline \multicolumn{3}{|l|}{ Fertilizantes foliares (Formulações) } \\
\hline 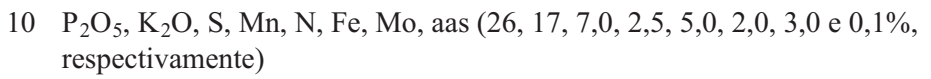 & Aminofós & \multirow{3}{*}{ RCN Agro } \\
\hline $11 \mathrm{Cu}$ e $\mathrm{Ca}(25$ e $10 \%)$ & Bordasul & \\
\hline $12 \mathrm{P}_{2} \mathrm{O}_{5}$ e $\mathrm{K}_{2} \mathrm{O}(28$ e $26 \%)$ & Goldfos & \\
\hline $13 \mathrm{P}_{2} \mathrm{O}_{5}$ e $\mathrm{K}_{2} \mathrm{O}(35$ e $22 \%)$ & Seyva Fértil & Batroff \\
\hline $14 \mathrm{~S}$ e $\mathrm{Ca}(50$ e $10 \%)$ & Sulfocal & RCN Agro \\
\hline $15 \mathrm{~K}_{2} \mathrm{O}, \mathrm{Cu}, \mathrm{Zn}, \mathrm{B}, \mathrm{Mg}, \mathrm{S}(10,10,8,2,3$, 1 e $10 \%$, respectivamente) & Viçosa Café & RCN Agro \\
\hline \multicolumn{3}{|l|}{ Hipocloritos } \\
\hline $16 \mathrm{NaClO}$ (Hipoclorito de sódio, $6 \%$ de $\mathrm{Cl}$ ativo) & Água Sanitária & Genco \\
\hline $17 \mathrm{CaOCl}_{2}$ (Hipoclorito de cálcio, $70 \%$ de $\mathrm{Cl}$ ativo) & Cloro de Piscina & $\underline{I}$ \\
\hline \multicolumn{3}{|l|}{ Benzothiadiazol ( BTH) } \\
\hline 18 Acibenzolar-S-Metil (ASM) & Bion & Syngenta \\
\hline \multicolumn{3}{|l|}{ Fungicida Sistêmico } \\
\hline 19 Tetraco nazole (Triazol) & Domark & Sipcam \\
\hline & & Agro \\
\hline \multicolumn{3}{|l|}{ Estrobi lurinas (classe química Oximinoacetato) } \\
\hline 20 Azoxystrobin & Amistar & Syngenta \\
\hline 21 Piraclostrobin & Comet & Basf \\
\hline 22 Trifloxystrobin & Flint & Bayer \\
\hline \multicolumn{3}{|l|}{ Misturas e Formulações Prontas } \\
\hline $23 \quad \mathrm{ASM}+$ Pyraclostrobin & I & I \\
\hline $24 \quad$ ASM + Azoxystrobin & I & I \\
\hline 25 Trifloxystrobin + Tebuconazol & Nativo & Bayer \\
\hline Testemunha 1 (água) & I & I \\
\hline 27 Testemunha 2 (Epoxiconazol + Pyraclostrobin) & Opera & Basf \\
\hline
\end{tabular}
${ }^{1}$ Extratos de folhas de café e de folhas, e sementes de neem obtidos por meio de processos de extração com água (A),
hexano (B) e metanol (M); ${ }^{2} \mathrm{I}$ - Indeterminado.

compostos, extratos foliares aquosos de café, hipoclorito de sódio (1200 mL/100L de água), tetraconazole, azoxystrobin, piraclostrobin, trifloxystrobin, acibenzolar-Smetil + pyraclostrobin, acibenzolar-S-metil + azoxystrobin, trifloxystrobin + ciproconazole e trifloxystrobin + tebuconazole reduziram igualmente o número de pústulas e de área foliar com ferrugem, porém nunca superior aos valores observados nos tratamentos epoxiconazole + piraclostrobin (testemunha 2). Dois compostos, extratos foliares metanólicos de sementes de Azadirachta indica e hipoclorito de sódio (600 mL/100 L de água), reduziram a severidade da ferrugem em mais de $94 \%$ em comparação a testemunha 1 (água) (Tabela 2). O composto Ecolife e os elementos $\mathrm{P}_{2} \mathrm{O}_{5}, \mathrm{~K}_{2} \mathrm{O}, \mathrm{S}, \mathrm{Mn}, \mathrm{N}, \mathrm{Fe}$, Mo, Aas (RCN); $\mathrm{Cu}, \mathrm{Ca}(\mathrm{RCN}) ; \mathrm{SiO}_{2}, \mathrm{TiO}_{2}, \mathrm{Al}_{2} \mathrm{O}_{5}, \mathrm{Fe}_{2}, \mathrm{MgO}, \mathrm{CaO}, \mathrm{P}_{2} \mathrm{O}_{5}, \mathrm{~S}$ (Ulmasud); $\mathrm{K}_{2} \mathrm{O}, \mathrm{Cu}, \mathrm{Zn}, \mathrm{B}, \mathrm{Mg}$, S (Nutriplant) e hipoclorito de cálcio (500 g/100 L de água) reduziram a severidade da ferrugem em até $73 \%$ em comparação a testemunha 1 (água). Esses tratamentos posicionaram-se como um grupo intermediário de compostos, pois foram capazes de reduzir a severidade da ferrugem, evidenciando o efeito protetor desses produtos nas dosagens utilizadas. 
Avaliação de produtos alternativos no controle da ferrugem do cafeeiro...

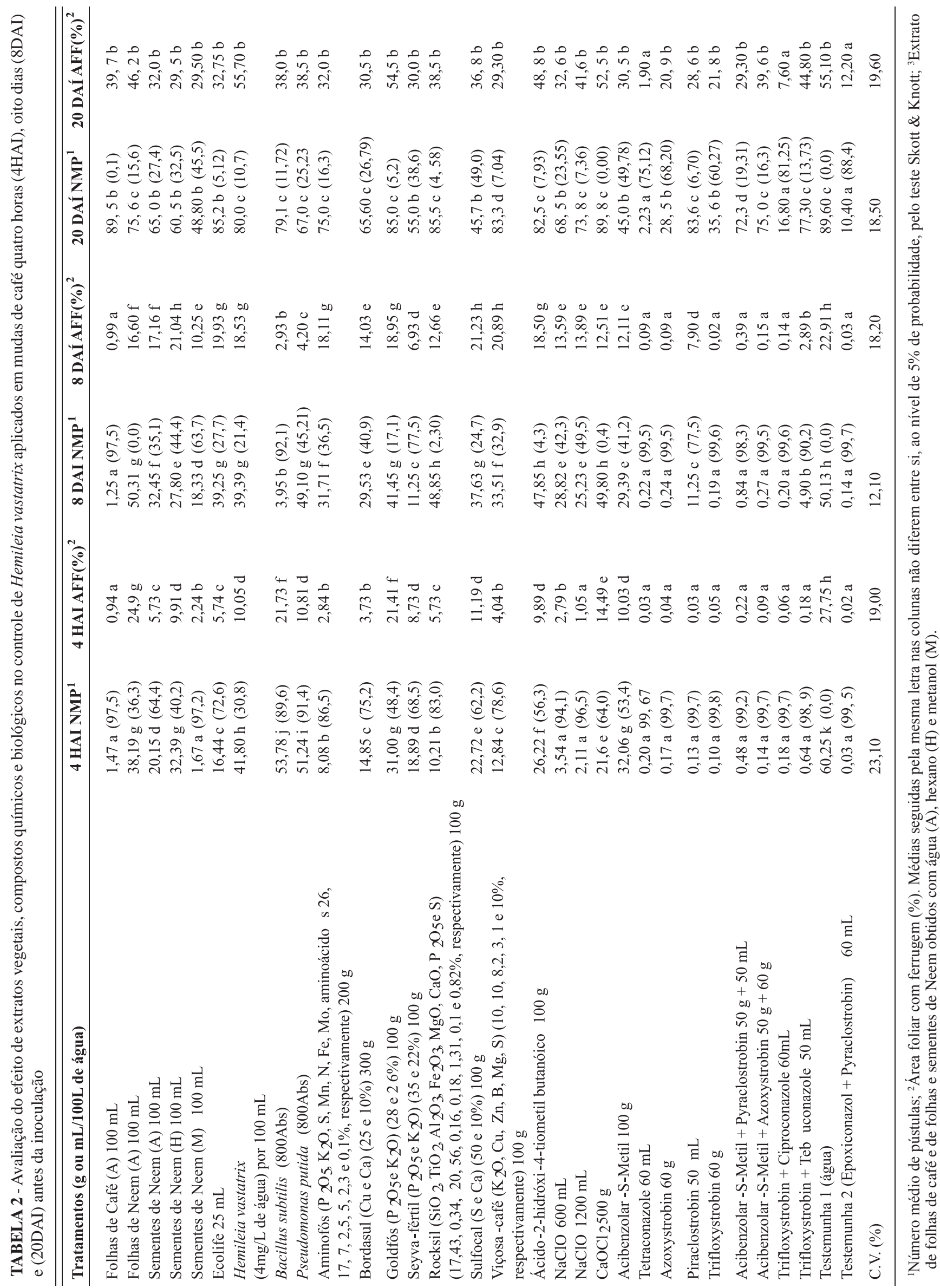

Fitopatol. Bras. 32(2), mar - abr 2007 
Os fertilizantes foliares e o produto Ecolife foram pesquisados como indutores de resistência em plantas contra doenças fúngicas. Extratos de folhas ou de sementes apresentaram resultados bastante diferentes já que substâncias ativas podem possuir solubilidades diferentes em água e outros solventes como o metanol e o hexano. Suspensões de células bacterianas ou de esporos fúngicos são capazes de induzirem resistência (Martins, 1991), entretanto, eles não têm exercem ação protetora conforme mostram os dados deste estudo. O mesmo pode ser atribuído ao indutor de resistência acibenzolar-S-metil. Os compostos utilizados, tanto naturais quanto artificiais, que foram capazes de reduzir a severidade da ferrugem para valores inferiores a $50 \%$ daquele observado no tratamento epoxiconazole + piraclostrobin talvez possam ter sua capacidade de controle aumentada com a utilização de doses um pouco maiores, mas que não causem sintomas de fitotoxidez. O hipoclorito de sódio foi mais eficiente do que o hipoclorito de cálcio, principalmente na dosagem de $1.200 \mathrm{~mL} / 100 \mathrm{~L}$.

Pela avaliação do efeito protetor observa-se que o efeito protetor é conferido de uma forma mais eficaz quando os extratos vegetais, hipocloritos e até fertilizantes foliares são utilizados. É bem possível que várias substâncias afetaram tanto o estabelecimento (número de pústulas) quanto à colonização (área foliar infectada) pelo fungo. Existe um contraste entre fungicidas, os quais já se conhecem as melhores formulações, os princípios ativos e as doses e, os outros produtos testados nesse estudo, cujas doses e formulações devem ser melhores pesquisados.

O acibenzolar-S-metil, como já esperado, não teve um bom efeito protetor mesmo nas maiores dosagens concordando com resultados de outros trabalhos (Cavalcanti et al., 2000; Guzzo et al., 2001; Marchi, 2002). Nem sempre o efeito de um composto químico obtido em condições de laboratório, corresponde com a sua performance ao nível de campo, devido à decomposição do produto em compostos pouco tóxicos, lavagem pela chuva e cobertura desuniforme na folhagem. Quando o acibenzolar-S-metil foi misturado ao fungicida pyraclostrobin ou azoxystrobin, o controle da ferrugem foi eficiente devido ao efeito das estrobirulinas do que do próprio acibenzolar-S-metil. As estrobilurinas exercem um efeito positivo no controle de alguns basidiomycetes (Margot et al., 1998).

A maioria dos compostos reduziu o número de pústulas e a área foliar com ferrugem em comparação à testemunha 1 (água) $(P \leq 0,05)$ (Tabela 2). Um total de sete compostos, extratos aquosos de folhas de café, tetraconazole, azoxystrobin, trifloxystrobin, acibenzolar-Smetil + piraclostrobin, acibenzolar-S-metil + azoxystrobin e trifloxystrobin + cyproconazole reduziram o número de pústulas e área foliar com ferrugem para valores similares, porém nunca superiores aos valores observados no tratamento epoxiconazole + piraclostrobin. Quatro Bacillus subtilis, Pseudomonas putida, acibenzolar-S-metil + trifloxystrobin + tebuconazole reduziram a severidade da ferrugem em mais de 90\% em relação à testemunha 1 (água). Três compostos, o produto Batroff, acibenzolar-S-metil e piraclostrobin reduziram a severidade da ferrugem em mais de $77 \%$ em relação à testemunha 1 (água). Uma indução de resistência sistêmica pode ter ocorrido tanto por compostos naturais como sintéticos, devido à presença, nesses compostos, de substâncias que protegem tecidos distantes do local de aplicação do produto que são os fungicidas sistêmicos. É possível que tanto os compostos naturais ou os artificiais que reduziram eficientemente a severidade da ferrugem, contenham ingredientes que são mobilizados para tecidos distantes protegendo as folhas superiores, as quais foram inoculadas, oito dias após a aplicação. O acibenzolar-Smetil, na melhor dose que foi de 25/100 L de água, não apresentou atividade fungicida concordando com relatos na literatura (Guzzo et al., 2001; Marchi, 2002). No que se refere à indução de resistência em plantas, deve-se separar o efeito fungitóxico das substâncias presentes nos compostos estudados da capacidade de servirem como indutores que atuam em rotas metabólicas de defesa, porém é bem possível que esses dois efeitos tenham ocorrido de maneira sinérgica. Nesta linha de raciocínio, tanto os fungicidas sistêmicos quanto os compostos naturais ou os fertilizantes foliares penetraram nas folhas baixeiras alcançando até em oito dias as folhas inoculadas na parte superior, ativando mecanismo(s) de defesa do cafeeiro. Acredita-se que essas duas situações tenham ocorrido conjuntamente se considerar que o efeito sistêmico dos fungicidas e a ativação de mecanismos de defesa da planta por diversos produtos.

Alguns compostos com ação protetora não apresentaram indução de resistência em comparação ao efeito do Bacillus subtilis, Pseudomonas putida e do acibenzolar-S-methyl nas doses de 25 e 50 g/100L. Sugerese em trabalhos futuros comprovar o efeito dos fungicidas como indutores de resistência, por meio da determinação da atividade de enzimas relacionadas com a patogênese. Em relação aos fertilizantes foliares, ressaltados pelos fabricantes como indutores de resistência, acredita-se que o efeito deles, esteja mais ligado ao aspecto nutricional que exercem nas plantas, podendo indiretamente refletir numa maior resistência à patógenos.

Os resultados desse trabalho mostraram que alguns dos compostos utilizados atuam direta e/ou indiretamente no processo infeccioso de $H$. vastatrix em cafeeiro. Estudos posteriores deverão elucidar como esses compostos afetam o fungo e o metabolismo da planta hospedeira.

\section{REFERÊNCIAS BIBLIOFRÁFICAS}

ANTONIW, W.J. \& WHITE, R. The effects of aspirin and polyacrylic acid on soluble leaf proteins and resistance to virus infection in five cultivars of tobacco. Phytopathology 98:331-341. 1980.

CAVALCANTI, L.S. Indução de resistência a Verticillium dahliae 
Kleb. em plântulas de cacaueiro por Benzotiadiazole (BTH). Dissertação de Mestrado. Lavras MG. Universidade Federal de Lavras. 2000.

COSTA, M.J.N., CAMPOS, V.P., PFENNING, L.H. \& OLIVEIRA, D.F. Toxicidade de filtrados fúngicos a Meloidogyne incognita. Fitopatologia Brasileira 26:749-755. 2001.

GUZZO, S.D., CASTRO, R.M., KYDA, K. \& MARTINS, E.M.F. Ação protetora do acibenzolar-S-methyl em plantas de cafeeiro contra ferrugem. Arquivo Instituto Biológico 68:89-94. 2001.

KESSMANN, H., STAUB, T., HOFMANN, C., MAETZKE, T. \& HERZOG, J. Induction of Systemic Acquired Disease Resistance in Plants by Chemicals. Annual Review of Phytopathology 32:439459. 1994.

KUSHALAPPA, A.C. \& CHAVES, G.M. Escala para avaliar a percentagem de área foliar com ferrugem do cafeeiro. Fitopatologia Brasileira 3:119. 1978. (Resumo)

MARCHI, C.E, BORGES, M.F. \& RESENDE, M.L.V. Proteção induzida por benzotiadiazole contra a ferrugem-alaranjada (Hemileia vastatrix) em cafeeiro. Ciência e Agrotecnologia 26:1103-1106. 2002.

MARGOT, P., HUGGENBERG, F., AMREIN, J. \& WEISS, B. A new broad-spectrum strobilurin fungicide. Brighton. Crop
Protection Conference on Plant Disease 375-383. 1998.

MARTINS, E.M.F. Controle da ferrugem do cafeeiro (Hemileia vastatrix) através da indução de resistência. In: Bettiol, W. (Ed.) Controle Biológico de Doenças de Plantas. Jaguariúna SP. Embrapa-CNPDA. 1991. pp. 345-363.

STADNIK, M. Indução de resistência a oídios. In: Resumos, XXIII Congresso Paulista de Fitopatologia 176-181. 2000.

STEIN A. \& LOEBENSTEIN G. Induced interference by synthetic polyanions with the infection of tobacco mosaic virus. Phytopathology 62:1461-1466. 1972.

VAN LOON, L.C., BAKKER, P.A.H.M. \& PIETERSE, C.M.J. Systemic resistance induced by rhizosphere bacteria. Annual Review of Phytopathology 36:453-483. 1998.

VEGRO, C.L.R. \& FERREIRA, C.R.R.P.T. Evolução das despesas com defensivos agrícolas e fertilizantes para a safra de café 2000/01 nos estados de São Paulo e Paraná. Informações Econômicas 30:53-59. 2000.

ZAMBOLIM, L. \& CHAVES, G.M. Efeito de baixas temperaturas e do binômio temperatura-umidade relativa sobre a viabilidade dos urediosporos de Hemileia vastatrix Berk. et Br. e Uromyces phaseoli typica Arth. Experientiae 17:151-184. 1974. 